\title{
Numerical analysis on tensile performance of bolted glulam joints with initial local cracks
}

\author{
Jing Zhang ${ }^{1} \cdot$ Min-Juan $\mathrm{He}^{1} \cdot$ Zheng Li $^{1}$
}

Received: 20 October 2017 / Accepted: 6 February 2018 / Published online: 13 March 2018

(C) The Japan Wood Research Society 2018

\begin{abstract}
Under varying climate conditions, cracks are commonly observed in bolted joints, owing to the shrinkage of wood and confinement from slotted-in steel plates and bolts. A three-dimensional finite element model was developed to investigate the mechanical behavior of bolted glulam joints with initial cracks. Wood foundation was prescribed in the model to simulate the local crushing behavior of wood surrounding the bolts. The behavior of wood in compression and the foundation were defined as transversely isotropic plastic in the software package ANSYS. Cohesive zone model was applied in the numerical analysis to consider the propagation of initial cracks and brittle failure of wood in the bolted joints under tension load. The numerical model was validated by the experiments conducted on full-scale specimens and it is indicated that the numerical model has good ability in predicting the failure modes and capacity of tension joints with local cracks. To further investigate the influence of crack number, length and locations, a parametric study was conducted with the verified model. Moreover, to study the effects of cracks on the behavior of bolted joints with different failure modes, another bolted joint including bolts with different strength grades and diameters was designed and analyzed in the parametric study, which was expected to have bolt yielding failure mode. It was found that the initial cracks can decrease the capacity and initial stiffness of tension joints by up to 16.5 and $34.8 \%$, respectively.
\end{abstract}

Keywords Bolted glulam joints $\cdot$ Crack $\cdot$ Numerical analysis $\cdot$ Cohesive zone model $\cdot$ Parametric study

\section{Introduction}

Timber joints are critical elements in timber structures and sometimes determine the load bearing capacity of the whole system [1]. To get a good knowledge of mechanical performance of timber joints, comprehensive experimental investigation and numerical analysis have been conducted by previous researchers. Steel-to-timber joints are commonly utilized in glulam structures. The capacity of this type of joints is determined by plastic moment capacity of fasteners and material properties of wood [2]. Some experimental researches were carried out on bolted glulam joints under tension load [3-6]. To further investigate the influence of different factors, such as joint geometry, strength or layout of fasteners, numerical approach was chosen by previous

Zheng Li

zhengli@tongji.edu.cn

1 Department of Structural Engineering, Tongji University, Shanghai 200092, China researchers due to the high cost and time-consuming characteristic of experimental tests.

To develop a finite element model of timber joints, the choice of material model is particularly important. Hill yield criterion was sometimes applied in numerical models of bolted glulam joints and wood in compression was modelled as an elasto-plastic orthotropic material [1, 7-9]. However, the constitutive law did not consider the brittle failure of wood. To improve the material model, several failure criterions of wood were proposed and applied in the analysis of timber joints. Maximum stress was one of the failure criterions used for wood in tension. In the numerical model of bolted joints developed by Kharouf [10], wood was assumed to be elasto-plastic in compression with Hill yield criterion and linear elastic in tension with maximum stress failure criterion. The failure modes and deformation obtained from the numerical analysis had a good agreement with the experimental results, while the stiffness was much greater than experimental values. Weibull weakest link theory is another method to consider brittle failure in timber joints, which was applied in [11]. The numerical model achieved a good 
prediction of load-displacement relationship, while the estimation of peak load was conservative. Modified Hill failure criterion [12] was also proposed to model brittle behavior of wood in tension and shear. A reduction of elastic modulus was included in the model to consider progressive failure of wood. Hoffman failure criterion is able to model damage evolution of wood. A numerical model was previously developed with the application of both Hill yield criterion and Hoffman failure criterion [1]. The ability of the model to predict behavior of timber joints was validated by comparison with experimental results. Tsai-Wu failure criterion, a common strength criterion in existence, is widely applied in anisotropic composite materials $[8,13]$. Different strengths in compression and tension can be taken into account in the criterion, while the stress interaction coefficients are sensitive to the applied test methods and difficult to determine [14]. However, the failure criterion cannot consider the softening law of wood induced by micro-cracking and fiber-bridging phenomena in the crack propagation process.

The local crushing behavior of wooden parts underneath fasteners is a common phenomenon in timber joints. A wood foundation model was proposed to develop a threedimensional finite element model of dowel joints [15]. The material constants of wood near bolt hole were derived by converting load-deformation relationship obtained from embedment test to a bilinear stress-strain relationship. The model has been applied into the numerical analysis of nailed joint [16] and post- and beam-joint [17], which indicated a good prediction of the load-displacement relationship. However, the model cannot be used to simulate fracture failure in timber joints such as wood splitting or crack growth process. In terms of crack propagation simulation, joint element with softening behavior was developed and set on the predicted crack propagation path [18]. To investigate the effect of tension and shear on the behavior of dowel joints, two joint elements were defined and set in two separate layers, respectively [19]. Cohesive zone material law was commonly used in the numerical analysis of the delamination of laminated composites [20-22]. In 2011, Bettina Franke applied cohesive zone material model to simulate the cracking process of wood in dowel connections loaded perpendicular to grain [23]. Contact element pairs were set on the potential crack plane and crack propagation was simulated by debonding the contact pairs and creating new surfaces in the model. In this way, the cracking process could be observed intuitively, which is quite helpful to understand the failure mechanisms of bolted joints.

Cracks are commonly observed in bolted joints as a result of variable climates and restrained strains caused by the existence of steel fasteners [24-26]. For bolted joints loaded parallel to grain, due to the existence of initial cracks, the failure of joints may switch from a ductile mode to a brittle one, and the external load cannot distribute evenly to all bolts. Thus, initial cracks may significantly influence the mechanical behavior of bolted joints. It is crucial to quantify the effect of initial cracks on the mechanical behavior of bolted joints. However, few reliable and feasible methods have yet been published to estimate the influence of cracks on bolted joints.

To study the influence of cracks on the mechanical behavior of joints, numerical analysis is an efficient way due to the time-consuming and high cost characteristic of experiments. To get a relatively accurate numerical result, the numerical model needs to reproduce the behavior of materials as close to the reality as possible. For bolted joint loaded parallel to grain, the main characteristics of its failure behavior include the ductile behavior like the embedding failure of wood underneath the bolts, and the brittle failure, such as the splitting and plug shear of wood along the bolt lines. For steelto-timber tension joints with initial cracks, in the numerical model developed in this paper, wood foundation model is applied to simulate local crushing behavior of wood underneath bolts. To consider the propagation of initial cracks and brittle failure of wood in the tension joints, cohesive zone material law was applied in the numerical modeling. The load-displacement curves and failure modes derived from full-scale experiment were used to validate the numerical results. Further, a relatively comprehensive parameter study was conducted to study the influence of different crack types on the mechanical behavior of bolted joints, which can provide theory basis when it comes to evaluate the safety and effectiveness of bolted glulam joints.

\section{Numerical modeling}

\section{Material modeling}

\section{Steel}

Isotropic plastic material model was applied to steel materials. The Poisson's ratio and Young modulus of steel were set as $v=0.3$ and $E=210,000 \mathrm{MPa}$, respectively. According to [1], the hardening of bolts did not obviously affect the behavior of joints, thus a bilinear stress-strain relationship was defined to represent the behavior of bolts, as shown in Fig. 1a. For bolts with strength grade of 10.9, the yield stress $f_{s}$ was set as $900 \mathrm{MPa}$ according to the previous research [27]. The hardening behavior of steel plate was proved to have dramatic influence on the behavior of joints by previous research [1], thus a nonlinear stress-strain relationship was defined in the model, which was obtained from tension test of steel plate. After simplifying the experimentally obtained curves as [1], the constitutive behavior of steel plate was presented in Fig. 1b. The stiffness gradually decreased to zero with the increase of strain after reaching the yield stress. The 
Fig. 1 The stress-strain relationship of fasteners: a bilinear stress-strain relationship of bolts; b nonlinear stress-strain relationship of steel plate

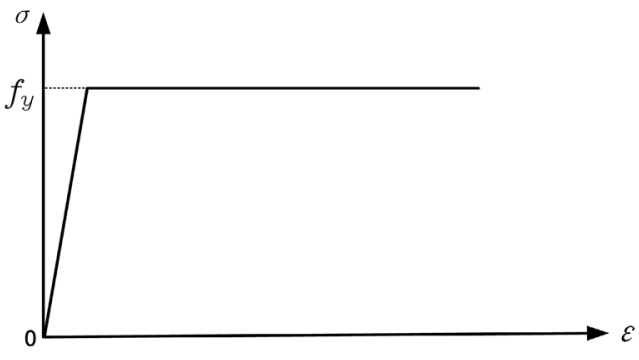

(a)

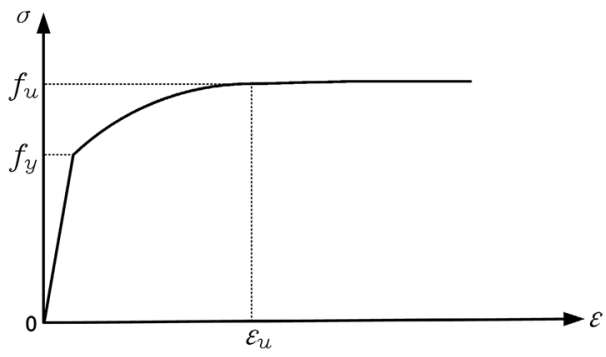

(b) yield stress $f_{s}$ and ultimate strength $f_{\mathrm{u}}$ of steel plate were set as 235 and $420 \mathrm{MPa}$, respectively. The corresponding strain at peak point $\varepsilon_{\mathrm{u}}$ was set as 0.12 .

\section{Wood in compression}

The behavior of wood in compression was assumed to be transversely isotropic plastic and Hill yield criterion with a bilinear stress-strain relationship was adopted for the constitutive modeling of wood. The Hill yield criterion can be expressed by stress components as:

$$
\begin{aligned}
f\left(\sigma, \sigma_{y}\right)= & a_{1}\left(\sigma_{22}-\sigma_{33}\right)^{2}+a_{2}\left(\sigma_{33}-\sigma_{11}\right)^{2} \\
& +a_{3}\left(\sigma_{11}-\sigma_{22}\right)^{2}+2 a_{4} \tau_{23}^{2}+2 a_{5} \tau_{31}^{2} \\
& +2 a_{6} \tau_{12}^{2}-\sigma_{y}^{2}=0
\end{aligned}
$$

Considering timber as a transversely isotropic material, the parameters in Eq. (1) are defined as:

$$
\begin{aligned}
& a_{1}=\left(\frac{\sigma_{y}}{\sigma_{22}^{y}}\right)^{2}-\frac{1}{2}\left(\frac{\sigma_{y}}{\sigma_{11}^{y}}\right)^{2} ; \quad a_{2}=a_{3}=\frac{1}{2}\left(\frac{\sigma_{y}}{\sigma_{11}^{y}}\right)^{2} ; \\
& a_{4}=\frac{1}{2}\left(\frac{\sigma_{y}}{\sigma_{23}^{y}}\right)^{2} ; \quad a_{5}=a_{6}=\frac{1}{2}\left(\frac{\sigma_{y}}{\sigma_{12}^{y}}\right)^{2}
\end{aligned}
$$

where $\sigma_{i}^{y}$ is the yield stress in the direction indicated by the value of subscript $i$, the isotropic yield stress $\sigma_{y}$ is an input constant for the hardening model, which was set equal to yield stress parallel to the grain $\sigma_{11}^{y}$. To simulate local crushing behavior of wood near the bolt hole, wood foundation model was applied in the numerical model. The nominal bilinear stress-strain relations of wood foundation were derived from embedment tests parallel and perpendicular to grain as [15], which was illustrated in Fig. 2. To simulate the behavior of wood foundation, the generalized Hill plasticity model was applied in the numerical analysis, which includes an anisotropic hardening rule. According to [17], the material constants were calculated as follows:

$\sigma_{\text {nom. }}=\frac{P_{y}}{d} \quad \varepsilon_{\text {nom. }}=\frac{W_{y}}{d} \quad K=\frac{P_{y}}{W_{y}}$

where $\sigma_{\text {nom. }}$ and $\varepsilon_{\text {nom. }}$ are the nominal yield stress (MPa) and strain $(\mathrm{mm} / \mathrm{mm})$ of the wood foundation, respectively; $P_{y}$ and $W_{y}$ are the yield load $(\mathrm{N} / \mathrm{mm})$ and deformation $(\mathrm{mm})$ in the bilinear load per unit length-embedment plot, as shown in Fig. 2; $K$ is the nominal modulus of wood foundation (MPa); $d$ is the bolt diameter ( $\mathrm{mm}$ ). The obtained nominal values were calibrated to be effective foundation properties as follows:

$$
\left(S_{\mathrm{FE}}\right)_{i}=\alpha_{i} \times K_{i} \quad\left(\varepsilon_{\mathrm{FE}}\right)_{i}=\frac{1}{\beta_{i}} \times\left(\varepsilon_{y}\right)_{i}
$$

Fig. 2 Experimental load per unit length-embedment curves and corresponding bilinear relationships

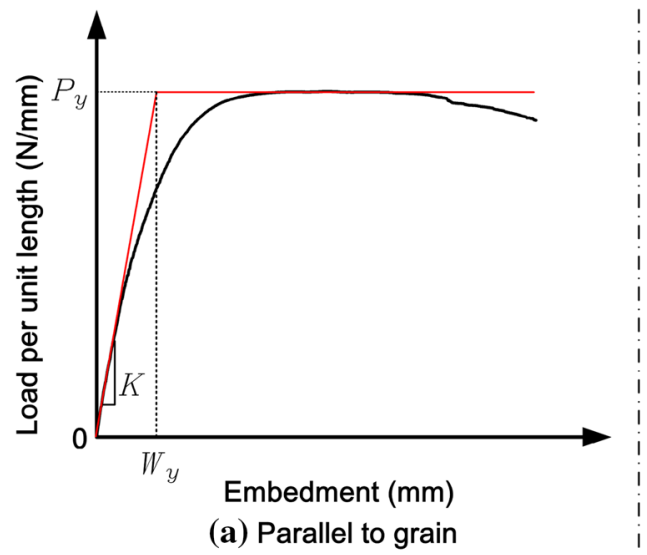

(a) Parallel to grain

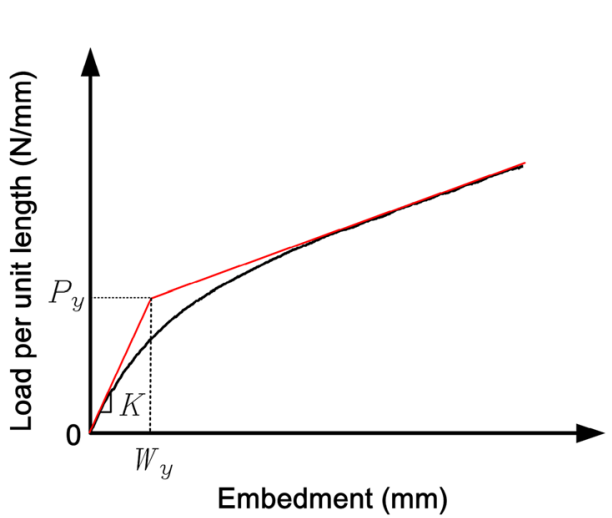

(b) Perpendicular to grain 
where $S_{\mathrm{FE}}$ and $\varepsilon_{\mathrm{FE}}$ are effective modulus and yield strain of the wood foundation, respectively; $\alpha_{i}$ and $\beta_{i}$ are calibration factors for the foundation modulus and yield strain, respectively; $i$ indicates the loading direction, which can be parallel $(\|)$ or perpendicular $(\perp)$ to grain direction. The calibration factors were determined based on the generalized calibration factors provided by Hong [15]. And iterative runs of bolt-embedment numerical analysis were conducted until numerical results were proved to be acceptable by comparison with the load-slip curves obtained from half-hole embedment tests in both parallel-to-grain and perpendicularto-grain directions. The shear modulus and yield point were determined by theoretical formulas as given in [28].

$G_{i j}=G_{j i}=\frac{\sqrt{E_{i} \times E_{j}}}{2 \times\left(1+\sqrt{v_{i j} \times v_{j i}}\right)} \quad\left(\gamma_{y}\right)_{i j}=\left(\gamma_{y}\right)_{j i}=\frac{\left(\sigma_{\text {int }}\right)_{i}}{1.98 \times E_{i}} \times \sqrt{\frac{E_{i}}{G_{i j}}}$

where $G$ and $\gamma_{y}$ are initial shear modulus and shear yield strain, respectively; $E$ is the effective modulus of wood foundation; $v$ is Poisson's ratio; $\sigma_{\text {int }}$ is the intercept of the second linear segment in the bilinear normal stress-strain curve. The tangent modulus of the hardening portion in compression and shear were set as $1 \%$ of initial modulus.

\section{Brittle failure of wooden parts}

For joints with initial cracks, crack propagation was visually observed in the experiment. The behavior may affect the load distributions among the bolts, and thus influence the behavior of the joints. For bolted joints under tension, splitting and plug shear failure of wood is a common failure mode, which always results in a sudden decrease of load-carrying capacity of joints. To simulate crack propagation and brittle failure in the joints, cohesive zone model was applied in the numerical analysis. In the FE-software ANSYS, surface-to-surface contact elements were set on the predicted crack growth path. Cohesive zone material (CZM) model with a bilinear traction separation law was defined to characterize the constitutive relation of the interface, which is shown in Fig. 3. For mode I fracture, perpendicular-to-grain tensile strength $f_{\mathrm{t}, 90}$, normal contact stiffness $K_{\mathrm{n}}$, and normal critical fracture energy $G_{\mathrm{c}}^{I}$ were defined in the constitutive relationship. Similarly, longitudinal shear strength $f_{\mathrm{s}}$, tangential contact stiffness $K_{\mathrm{t}}$, and tangential critical fracture energy $G_{\mathrm{c}}^{I I}$ were set for mode II fracture. Contact stiffness $K_{\mathrm{n}}$ and $K_{\mathrm{t}}$ are always acted as a penalty parameter, and the values are always quite high to prevent interpenetration of the element faces. The perpendicular-to-grain tensile strength $f_{\mathrm{t}, 90}$ and shear strength in the grain direction $f_{\mathrm{s}}$ were obtained from material property test conducted with small clear specimens, and Weibull theory was applied to consider the volume effect. $u_{\mathrm{n}}$ and $u_{\mathrm{t}}$ represent normal contact gap and tangential slip distance, respectively. For pure mode I or mode II fracture, complete debonding occurs when the gap $u_{\mathrm{n}}$ or $u_{\mathrm{t}}$ reaches its critical value $u_{\mathrm{n}}^{c}$ or $u_{\mathrm{t}}^{c}$. In the numerical analysis, mixed mode fracture was considered and a combined energy criterion was applied to determine the completion of debonding, expressed as follows:

$\frac{G_{\mathrm{I}}}{G_{c}^{\mathrm{I}}}+\frac{G_{\mathrm{II}}}{G_{c}^{\mathrm{II}}}=1$

where $G_{\text {I }}$ and $G_{\text {II }}$ represent the normal and tangential fracture energies, respectively. To apply CZM model in business software ANSYS, only the fracture energy and corresponding material strength are needed to be defined and input in the model.

\section{Finite element model}

Considering the initial cracks appeared in actual glulam structures, in the depth direction, cracks always propagate within one lumber and seldom cracks would pass through
Fig. 3 Cohesive zone material behavior

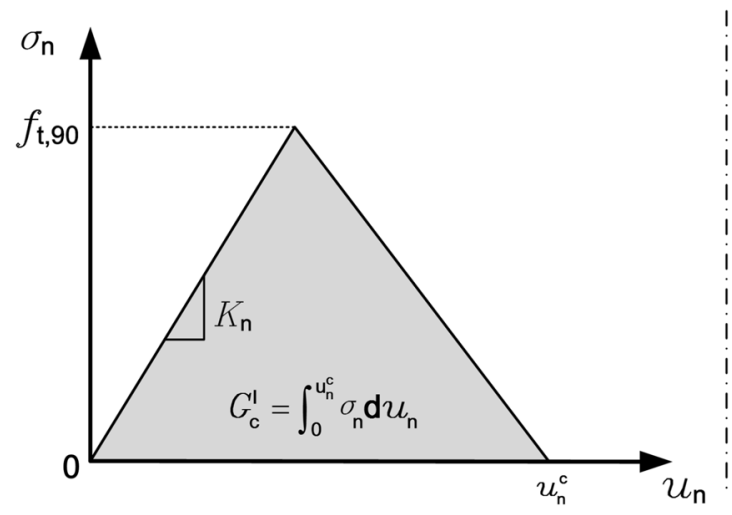

(a) Fracture mode I

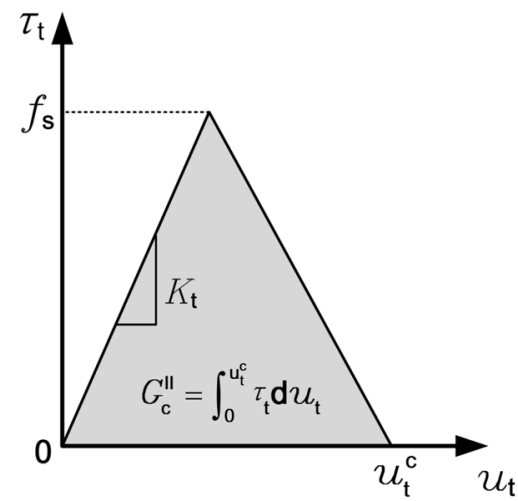

(b) Fracture mode II 
the glue lines. Thus, the glue lines are not included in the numerical model of bolted joints and the material property of glulam is assumed to be transversely anisotropic. Solid element SOLID185 with eight nodes defined in FEsoftware ANSYS was used to embody the joints. Surfaceto-surface contact elements CONTA174 and TARGE170 were used to define the interaction between timber and bolts, timber and steel plate, and bolts and steel plate. The friction coefficients on the contact interface were taken as 0.3 and 0.001 for wood-to-bolt and bolt-to-steel plate contacts, respectively [1]. The friction between timber and steel plate was neglected in the model. In the numerical model, the sizes of glulam members are $352.5 \mathrm{~mm}$ in length and $240 \times 90 \mathrm{~mm}$ in cross section. Bolts with strength grade of 10.9 and diameter of $14 \mathrm{~mm}$ are applied

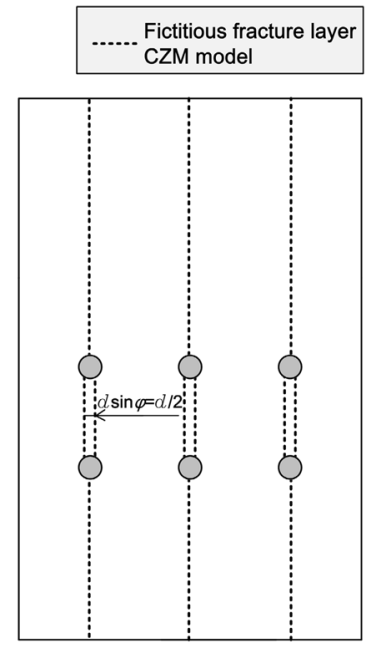

(a) without initial cracks

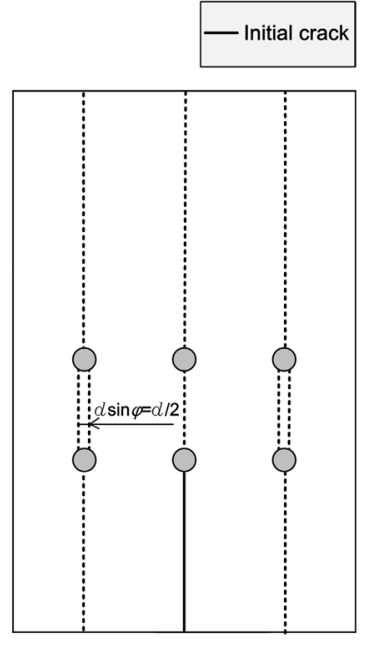

(b) with initial cracks
Fig. 4 The layouts of fictitious fracture layers in joints with or without initial cracks in the joint, which has a nominal yield stress of $900 \mathrm{MPa}$ according to Chinese code [27]. Different material models are set for different wooden parts in the joint area. Near the bolt holes, a cylinder with a radius of 1.8 times of bolt diameter was set along the length of the bolt, named as wood foundation zone. Contact pairs with CZM model were set on the predicted crack growth paths, which were determined based on the experimental phenomenon. Under the tension load, splitting and plug shear failure were observed in wooden parts underneath the first and second bolt row, respectively, and the cracks extended to the end of the glulam specimens. Thus, the assumed crack growth paths in the numerical model are shown in Fig. 4. In terms of plug shear failure, a block of wood with width of $d \sin \varphi$ is assumed to be plugged out by the bolt, where $d$ is the diameter of bolts and $\varphi=30^{\circ}$ is determined as in [29] by considering the friction between wood and bolt. This is validated by a linear elastic numerical analysis, which indicates high shear stress distributed along the fictitious fracture layers. The remaining wooden parts were assumed to be orthotropic linear elastic. The isotropic plastic material model was applied to bolts and steel plate. The distribution zone with different material models is shown in Fig. 5. The material constants used in this model are listed in Table 1. A displacement control loading was applied on the top end of the glulam elements and the displacement of steel plate on the other end was fixed. The numerical model with boundary conditions is presented in Fig. 6 .

\section{Test results and model verification}

To validate the numerical model proposed in this research, three configurations of bolted joints were designed and seven replicates were tested for each configuration. The joints on the top were designed much stronger than the bottom to ensure that failure occurs at the same end and initial cracks
Fig. 5 The distribution zones of material modeling in the joints

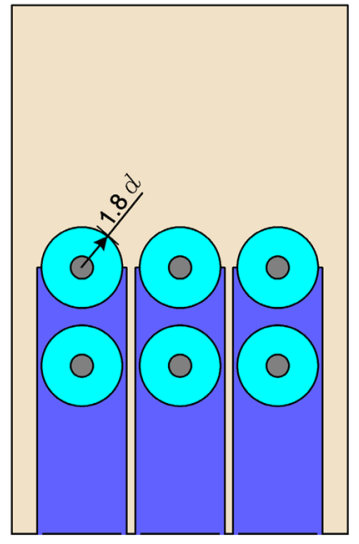

(a) Front view

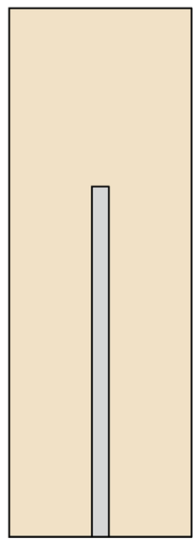

Orthotropic linear elastic (Glulam member) Wood foundation zone Bilinear isotropic plastic (Bolt) Transversely isotropic plastic Noninear isotropic plastic (Steel plate) 
Table 1 Material constants applied in this model

\begin{tabular}{|c|c|c|c|c|}
\hline Component & Bolt & Steel plate & Wood & Wood foundation \\
\hline Modulus of elasticity $\left(\mathrm{N} / \mathrm{mm}^{2}\right)$ & $E=2.1 \times 10^{5}$ & $E=2.1 \times 10^{5}$ & $\begin{array}{l}E_{\mathrm{L}}=1.02 \times 10^{4} \\
E_{\mathrm{R} ; \mathrm{T}}=510\end{array}$ & $\begin{array}{l}E_{\mathrm{L}}=1.04 \times 10^{3} \\
E_{\mathrm{R} ; \mathrm{T}}=103\end{array}$ \\
\hline Modulus of rigidity $\left(\mathrm{N} / \mathrm{mm}^{2}\right)$ & - & - & $\begin{array}{l}G_{\mathrm{LT} ; \mathrm{LR}}=1.01 \times 10^{3} \\
G_{\mathrm{RT}}=177\end{array}$ & $\begin{array}{l}G_{\mathrm{LT} ; \mathrm{LR}}=146 \\
G_{\mathrm{RT}}=36\end{array}$ \\
\hline Poisson ratio & $v=0.3$ & $v=0.3$ & $\begin{array}{l}v_{\mathrm{LT} ; \mathrm{LR}}=0.37 \\
v_{\mathrm{RT}}=0.44\end{array}$ & $\begin{array}{l}v_{\mathrm{LT} ; \mathrm{LR}}=0.37 \\
v_{\mathrm{RT}}=0.44\end{array}$ \\
\hline Yield stress $\left(\mathrm{N} / \mathrm{mm}^{2}\right)$ & $f_{y}=900$ & $f_{y}=235$ & $\begin{array}{l}\sigma_{y}=23.50 \\
\sigma_{\mathrm{L}}=23.50 \\
\sigma_{\mathrm{R} ; \mathrm{T}}=3.68 \\
\sigma_{\mathrm{LT} ; \mathrm{LR}}=5.7 \\
\sigma_{\mathrm{RT}}=1.6\end{array}$ & $\begin{array}{l}\sigma_{\mathrm{L}}=20.58 \\
\sigma_{y}=20.58 \\
\sigma_{\mathrm{R} ; \mathrm{T}}=5.09 \\
\sigma_{\mathrm{LT} ; \mathrm{LR}}=5.5 \\
\sigma_{\mathrm{RT}}=2.8\end{array}$ \\
\hline Strengths $\left(\mathrm{N} / \mathrm{mm}^{2}\right)$ & - & - & $\begin{array}{l}f_{t ; 90}=2.7 \\
f_{s}=5.7\end{array}$ & $\begin{array}{l}f_{t ; 90}=2.7 \\
f_{s}=5.7\end{array}$ \\
\hline Fracture energies $(\mathrm{N} / \mathrm{mm})$ & - & - & $\begin{array}{l}G_{c}^{\mathrm{I}}=0.24 \\
G_{c}^{\mathrm{II}}=0.55\end{array}$ & $\begin{array}{l}G_{c}^{\mathrm{l}}=0.24 \\
G_{c}^{\mathrm{II}}=0.55\end{array}$ \\
\hline
\end{tabular}

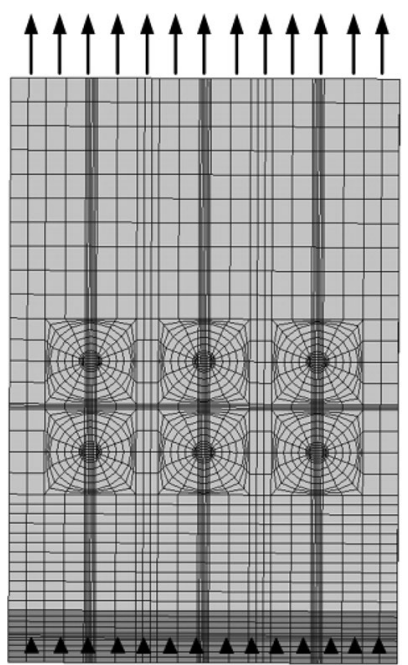

Fig. 6 Meshing and boundary conditions of the numerical model

were set on the bottom end to investigate the influence on the mechanical performance of joints. The stacking direction of the lamella in the experimental specimens is set and shown in Fig. 7 and the position of initial crack is avoided to overlap the glue lines. Detailed information of the joints on the bottom is shown in Fig. 8. Initially perfect Joint 1-1 was used for reference, initial cracks on one side and both sides of the steel plate were set in Joint 1-2 and Joint 1-3, respectively. The initial cracks were set along bolt lines and the crack depth was set from the front surface of the glulam specimen to the inner slot, which was based on the experimental research conducted by Sjödin [26]. The length and depth of the initial cracks through a bolt is set as 97 and $38.5 \mathrm{~mm}$, respectively. The material properties of wood in the specimens were obtained by individual material test and used as the material parameters in the numerical modeling, as shown in Table 1. The tension tests were conducted

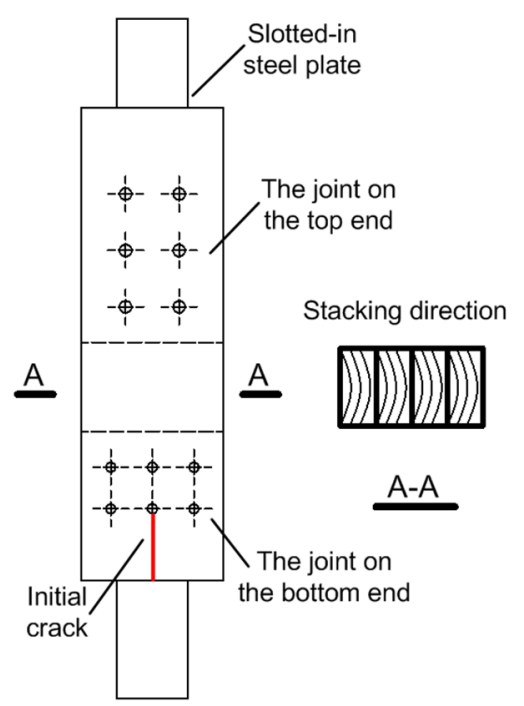

Fig. 7 The stacking direction of lamella in the experimental specimens

according to ASTM D1761-12 [30]. All the specimens were loaded continuously at a constant rate of $0.9 \mathrm{~mm} / \mathrm{min}$ until failure occurred. The failure modes of these three joints are shown in Fig. 8. Brittle failures like plug shear and splitting of wooden parts were observed in Joint 1-1, as shown in Fig. 9a. In Joints 1-2 and 1-3, the initial cracks propagated parallel to grain along the middle bolt line and brittle failure of wood along the side bolt lines occurred with the further application of tension load, as shown in Fig. 9b. The bolts were stiff and strong enough and thus, no bolt bending was observed, as can be seen in Fig. 9c.

The numerical model was developed to simulate the mechanical performance of joints with the same configurations and crack patterns in the tests. A comparison between numerical and test results was conducted 
Fig. 8 Detailed configurations of different crack types (dimensions are in $\mathrm{mm}$ )

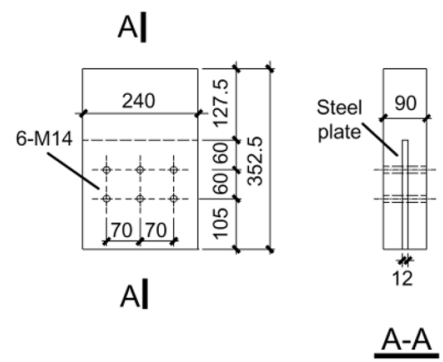

(a) Joint 1-1

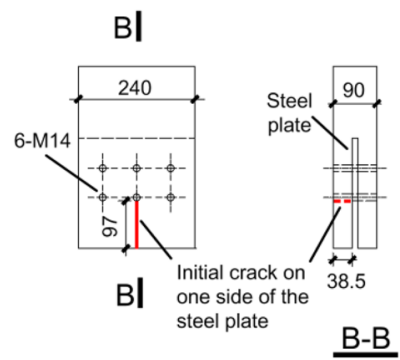

(b) Joint 1-2

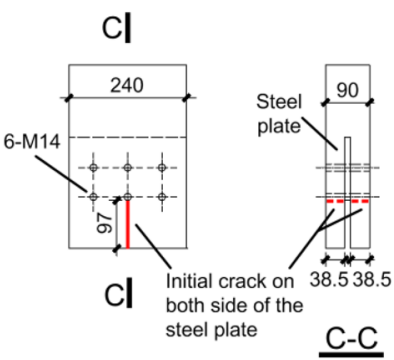

(c) Joint 1-3
Fig. 9 Failure modes of tension joints: a failure of wooden parts in Joint $1-1 ; \mathbf{b}$ failure of wooden parts in Joint 1-2 and Joint 1-3; c deformation of bolts and bolt holes (a)

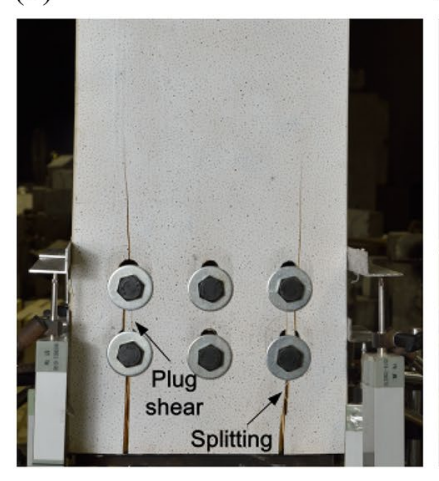

(b)

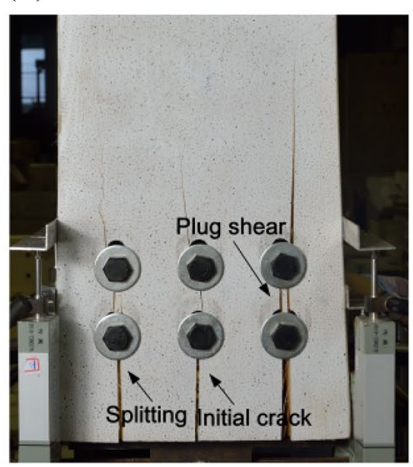

(c)

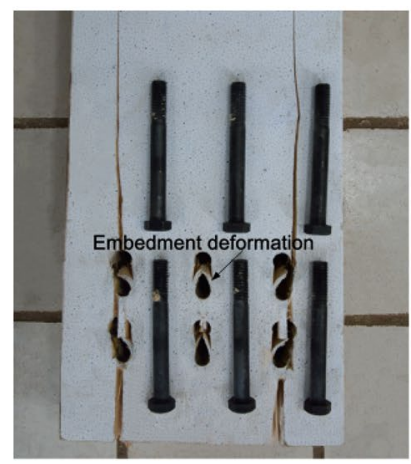

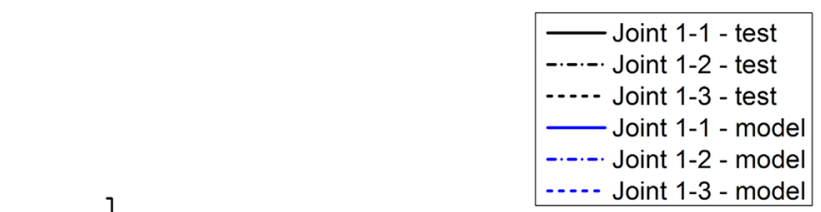

Table 2 Mechanical parameters obtained from experiments and numerical analysis

\begin{tabular}{llrr}
\hline Component & $\begin{array}{l}\text { Joint 1-1 } \\
\text { EXP } \\
\text { (NUM) }\end{array}$ & $\begin{array}{l}\text { Joint 1-2 } \\
\text { EXP } \\
(\text { NUM })\end{array}$ & \multicolumn{1}{l}{$\begin{array}{l}\text { Joint 1-3 } \\
\text { EXP } \\
(\text { NUM })\end{array}$} \\
\hline Initial stiffness $(\mathrm{kN} / \mathrm{mm})$ & $100(148)$ & $80(140)$ & $71(138)$ \\
Peak bearing capacity $(\mathrm{kN})$ & $192(199)$ & $182(193)$ & $169(183)$ \\
\hline
\end{tabular}

EXP indicates the values obtained from experiments; NUM represents the values derived from numerical analysis

peak load-bearing capacity and the deviation is within $8 \%$. However, the initial stiffness obtained from numerical analysis is larger than the experimental values. There are several factors which contributes this deviation. The first one is the variability in properties of wood in the test specimens. In the numerical model, the calibration factors of wood foundation were obtained from half-hole embedment tests, which were conducted with small clean specimens. Another possible reason is the bolt clearance existed in the test specimens. In the numerical modeling, the clearance was not considered to improve the convergence of the numerical analysis. Based on previous researches [31, 32], the bolt clearance would decrease the stiffness of bolted joints due to the lower final contact area between the bolt and wood. Moreover, in the test specimens, initial cracks with width of $1 \mathrm{~mm}$ were manually made by a wire saw. However, in the development of 


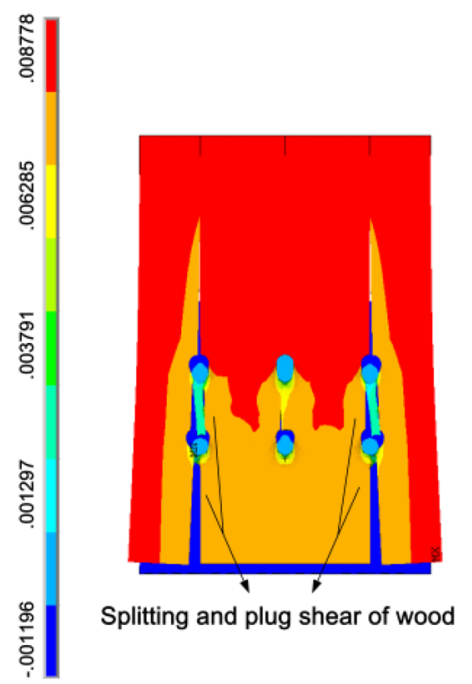

(a)

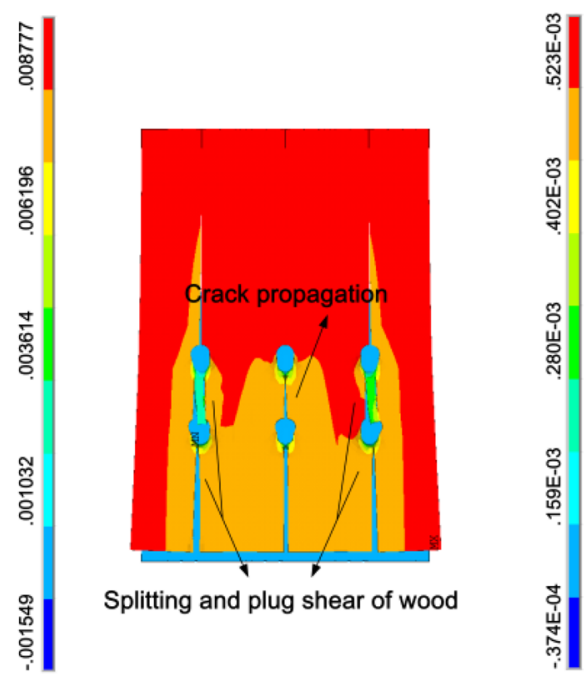

(b)
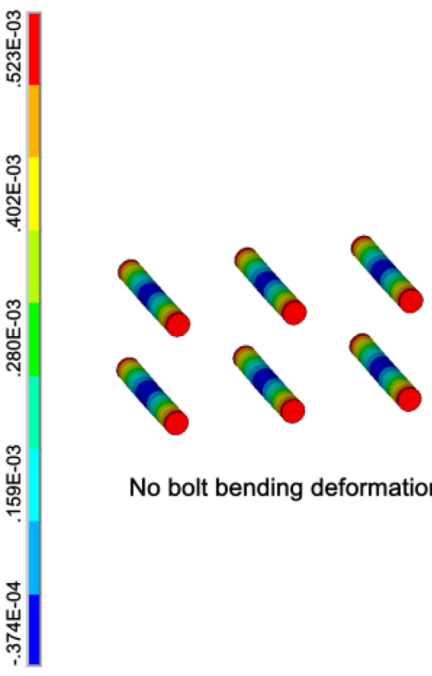

No bolt bending deformation

(c)

Fig. 11 Displacement plots in the grain direction of tension joints: a failure of wooden parts in Joint 1-1; b failure of wooden parts in Joint 1-2 and Joint 1-3; $\mathbf{c}$ deformation of bolts in Joint 1

numerical model, the width of initial cracks was set to be zero for convenience, which would lead to a higher initial stiffness from the numerical analysis. For initially perfect Joint 1-1, a sudden drop of capacity occurs after reaching the peak point with splitting failure of wood occurring on side bolt lines. However, a relatively small decrease of capacity is observed in the test curve. The main reason for this discrepancy is the uneven properties of wood in the test specimens and splitting failures of wooden parts at the symmetrical positions do not occur simultaneously in the experiment. The slip at the peak point of numerical curves is smaller than the experimental values, which is due to the variability in properties of wood in the test specimens.

The failure modes obtained from the numerical analysis are shown in Fig. 11. Plug shear and splitting failure
Al

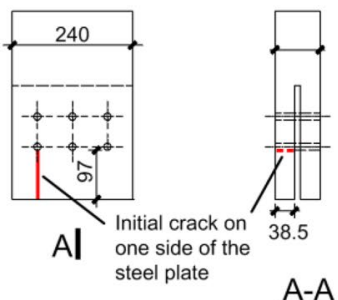

A-A

(a) Crack notation: LS1

El

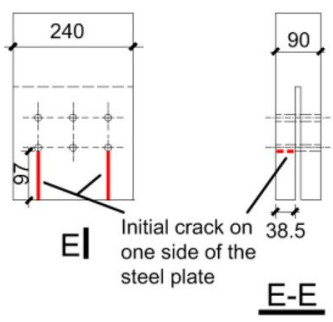

(e) Crack notation: RLS1
B

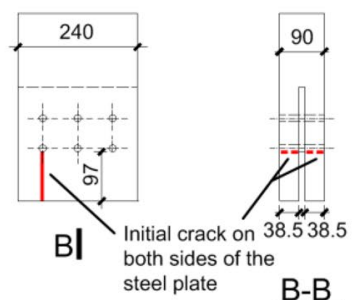

(b) Crack notation: LD1

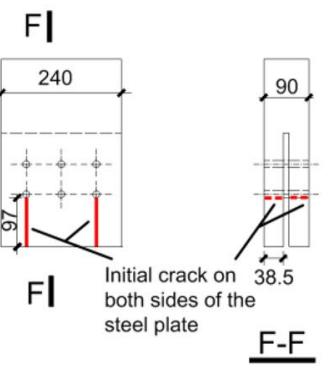

(f) Crack notation: RLD1
Cl
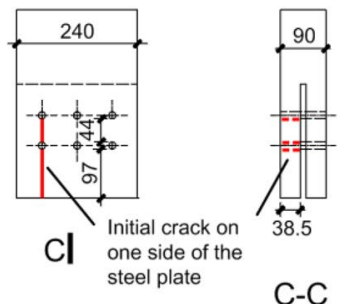

(c) Crack notation: LS2

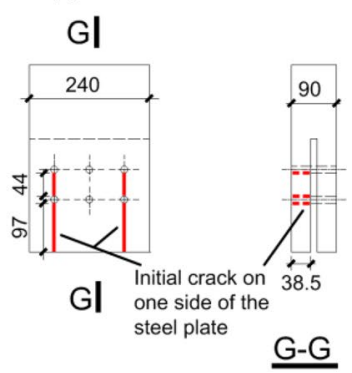

(g) Crack notation: RLS2

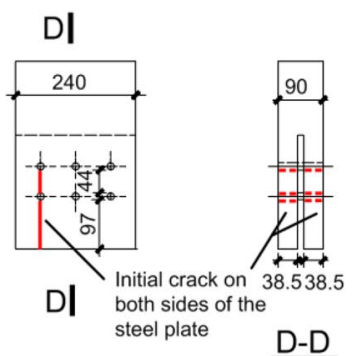

(d) Crack notation: LD2

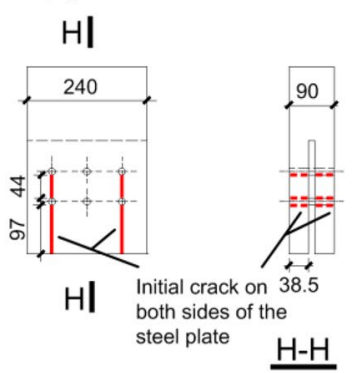

(h) Crack notation: RLD2

Fig. 12 The crack patterns considered in the parametric study (dimensions are in $\mathrm{mm}$ ) 
of wooden parts in the outer bolt lines occur in Joint 1-1, similar to the experimental observations. In Joint 1-2 and Joint $1-3$, the propagation of initial cracks and brittle failure of wood are quite close to the failure modes observed in the experiments, and no obvious bolt bending deformation is observed in the numerical analysis, which indicates the feasibility of this numerical model to predict the mechanical behavior and failure modes of bolted glulam joints.

\section{Parametric study}

A parametric study was conducted with the validated numerical model. The study focused on the influence of different crack patterns on bolted glulam joints with different failure modes. In the above analyzed Joints 1-1 1-3, the main observed failure modes are plug shear and splitting failure of wooden parts. To investigate the effects of cracks on the behavior of bolted joints with ductile failure modes, bolts with strength grade of 5.6 and diameter of $12 \mathrm{~mm}$ were used in Joint 2, which has nominal yield strength $300 \mathrm{MPa}$ according to Chinese code [27]. In terms of crack type, different crack lengths, crack locations and crack numbers were considered in the analysis. The detailed information of different crack patterns is shown in Fig. 12. The crack notation consists of three parts, which are "A", "B", "C", respectively. "A" indicates the bolt lines cracks located in, ' $\mathrm{L}$ ' and ' $\mathrm{M}$ ' stand for cracks set in left and middle bolt line, respectively, and 'RL' means cracks are set in both right and left bolt lines; " $B$ " describes the crack location, 'S' and ' $D$ '

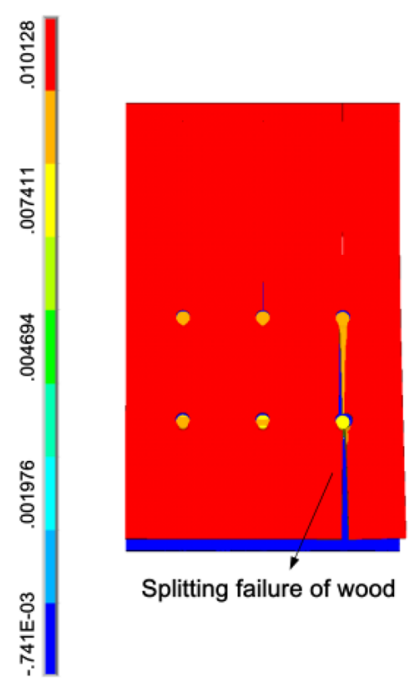

(a)

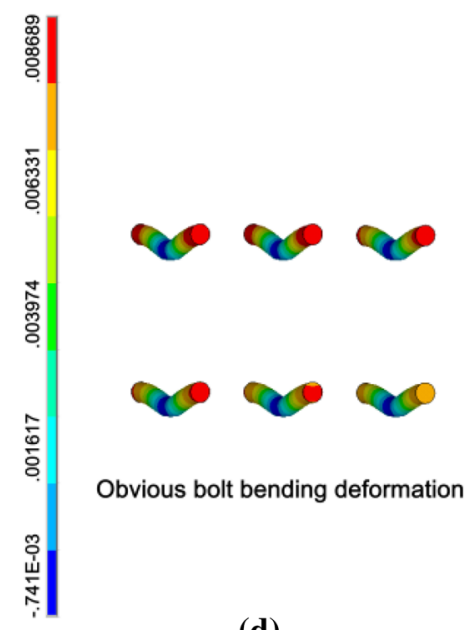

(d)
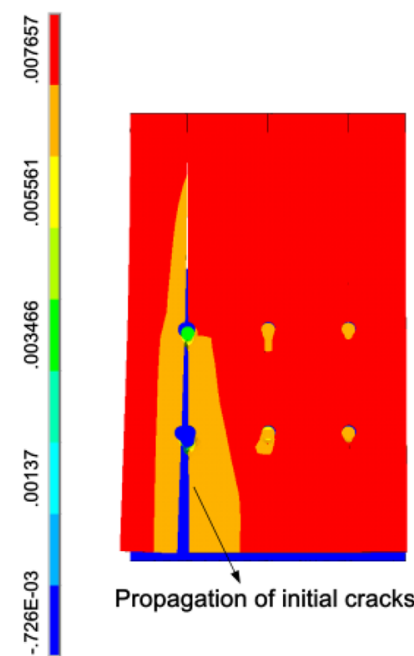

(b)
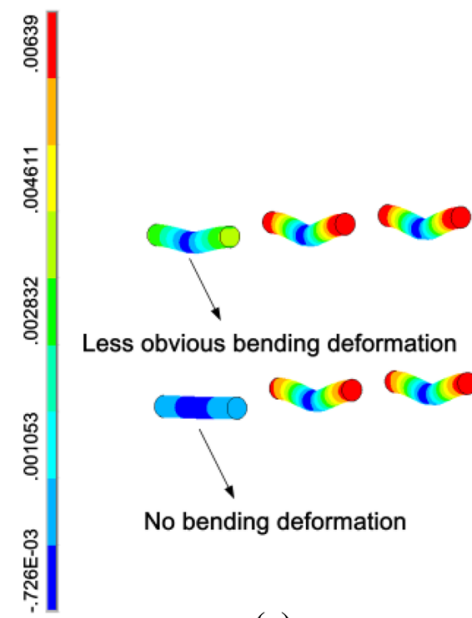

Less obvious bending deformation

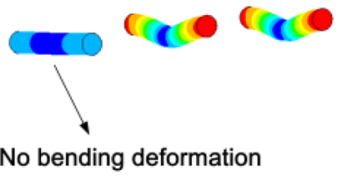

(e)
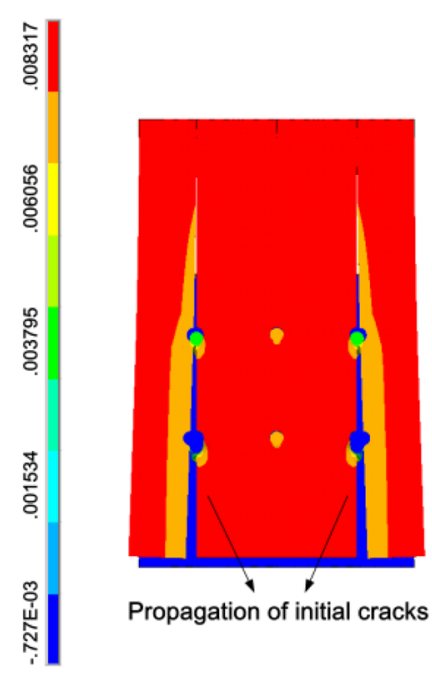

Propagation of initial cracks

(c)
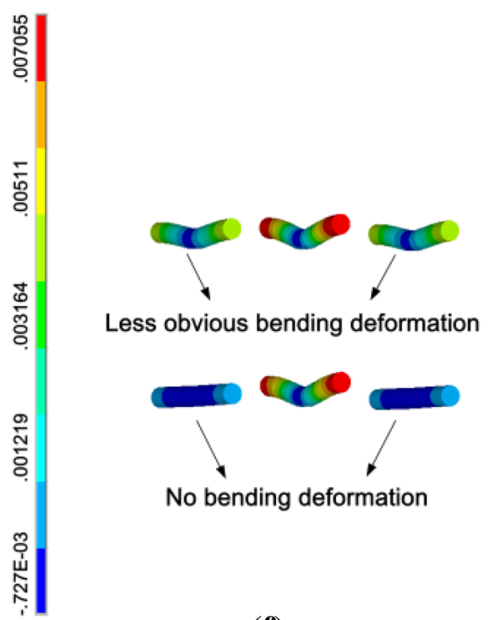

(f)
Fig. 13 Displacement plots in the grain direction of tension joints: a failure of wooden parts in Joint 2 without initial cracks; $\mathbf{b}$ failure of wooden parts in Joint 2 with crack LD1; c failure of wooden parts in Joint 2 with crack LRD1; d deformation of bolts in Joint 2 without initial cracks; e deformation of bolts in Joint 2 with crack LD1; $\mathbf{f}$ deformation of bolts in Joint 2 with crack LRD1 

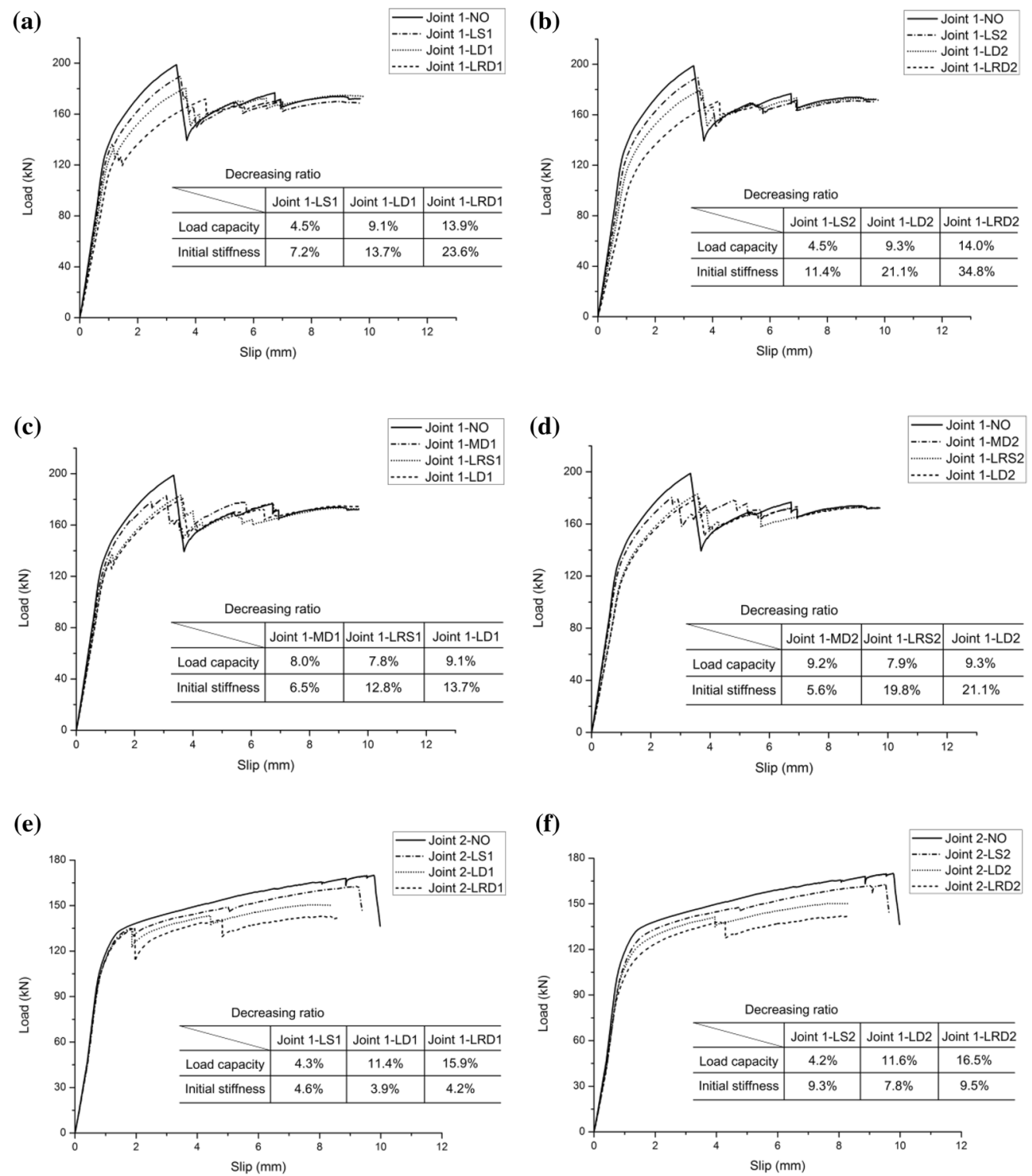

(g)

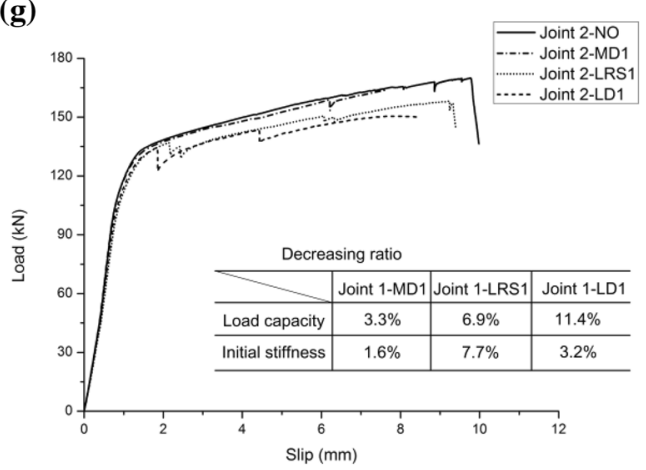

Fig. 14 Comparisons of load-slip curves for Joint 1 and Joint 2: a Joint 1 with different numbers of initial cracks through a bolt; b Joint 1 with different numbers of initial cracks through two bolts; $\mathbf{c}$ Joint 1 with two initial cracks through a bolt that have different crack locations; d Joint 1 with two initial cracks through two bolts that have (h)

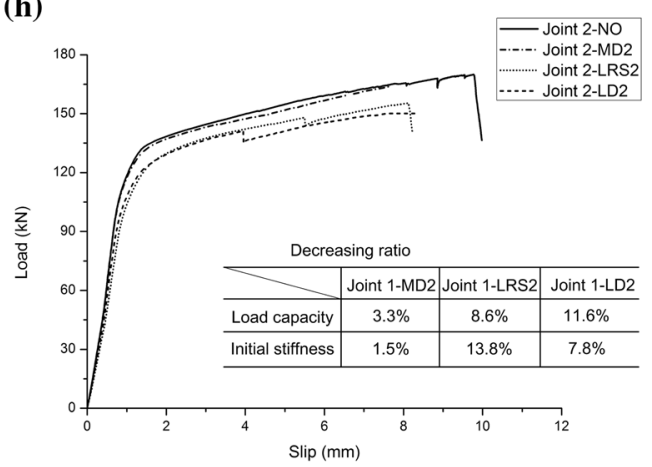

different crack locations; e Joint 2 with different numbers of initial cracks through a bolt; f Joint 2 with different numbers of initial cracks through two bolts; g Joint 2 with two initial cracks through a bolt that have different crack locations; $\mathbf{h}$ Joint 2 with two initial cracks through two bolts that have different crack locations 
indicates cracks set on one side and both sides of the steel plate, respectively; and " $\mathrm{C}$ " represents the crack length, the number ' 1 ' and ' 2 ' indicates cracks through one bolt and two bolts, respectively.

For Joint 2, bolt bending deformation is observed in the initially perfect joint, as shown in Fig. 13d, and splitting of wood in the right bolt line occurs under further application of tension load, as can be seen in Fig. 13a. In Joint 2 with initial cracks, propagation of cracks is commonly observed, as shown in Fig. 13b, c. For Joint 2 with crack pattern LD1, no bending deformation can be seen in the left bottom bolt under the tension load and less bending deformation is observed in the left top bolt, as shown in Fig. 13e, which is caused by crack opening and propagation. Similarly, for Joint 2 with crack pattern LRD1, no bending deformation can be seen in the left and right bottom bolts and those responding bolts on the top row are less bent than the bolts in the middle line, owing to the existence of cracks, as shown in Fig. 13f.

To further quantify the influence of different numbers of cracks, crack locations and crack lengths on the mechanical performance of Joint 1 and Joint 2, the comparisons of load-slip curves for bolted joints with different crack patterns are presented in Fig. 14. Further, the decreasing ratios of capacity and initial stiffness of bolted glulam joints are calculated and listed in the figure, which are obtained by dividing the decrease of these two mechanical parameters caused by initial cracks to those values of initially perfect joints. Figure 14a, b conduct a comparison of the behavior of Joint 1 with different numbers of cracks. Joint 1 with crack pattern LS1, LD1 and LRD1 include single crack, two cracks and four cracks in the joint, respectively. Cracks through one bolt are considered in Fig. 14a, as can be seen from the figure, the capacity and initial stiffness of bolted glulam joints are affected by initial cracks, and more decrease of these two mechanical parameters occurs in the joints with more cracks. The opening and propagation of initial cracks are observed gradually with the application of external load. For the bolts with cracks passing through, the crack opening leads to the decrease of contact area between bolts and wood in the dowel-embedment zone, which will affect the boltto-wood interaction and thus, more decrease of capacity is observed in joints with more cracks. Further, with the crack opening, the wood near the bolt holes cannot carry the load as a whole, which is a main reason for the decrease of initial stiffness of the bolted joints. For Joint 1 with crack pattern LRD1, the decreasing ratios of capacity and initial stiffness can be up to $13.9 \%$ and $23.6 \%$, respectively. Before reaching the peak point, a drop of capacity can be found in joints with initial cracks, which is caused by crack propagation. Initial cracks through two bolts are considered in Fig. 14b. Similar decreasing trend of initial stiffness and capacity can be found for the joints with more initial cracks. For Joint
1 with crack pattern LRD2, the decreasing ratios of the capacity and initial stiffness can be up to $14.0 \%$ and $34.8 \%$, respectively. Compared to Fig. 14a, it can be seen that different crack lengths have similar influence on the capacity of bolted joints, while longer cracks in Fig. 14b affect the initial stiffness of joints more dramatically. As can be seen from Fig. 14a, for joints with initial cracks through one bolt, crack propagation occurs before reaching the peak point, and the cracking conditions of the joints at the peak point are similar to those with initial cracks through two bolts. Thus, no significant difference is observed in the capacity of joints with initial cracks of different lengths. However, before the propagation of initial cracks, the opening displacements of longer cracks are more significant, and thus, the initial stiffness of joints is affected by the length of initial cracks.

Figure $14 \mathrm{c}$, d present the load-slip curves of Joint 1 with different crack locations. Two initial cracks through one bolt are considered in Fig. 14c. As shown in the figure, initial cracks at different locations reduce the capacity of bolted joints to a similar extent, while the cracks set on side bolt lines have more influence on the initial stiffness of tension joints than those set on middle line. When initial cracks are set in the middle bolt line, due to the symmetry of joints about the middle line, the crack opening is restrained by the wood on both sides of the symmetrical axis. Thus, the decrease of initial stiffness induced by cracks set on middle line is less significant than other cases. Further, from the load-slip curves, it can be found that the drop of capacity before reaching the peak point occurs much earlier in Joint 1 with crack pattern LD1 and LRS1 than that with crack pattern MD1. It indicates that the propagation of cracks set on side bolt lines more easily occurs than those on middle line. Two initial cracks through two bolts are considered in Fig. 14d. As can be observed from the figure, the joints with initial cracks at different locations have similar capacities, and cracks on side bolt lines decrease the initial stiffness of joints more significantly than those on middle line. The decreasing ratio of initial stiffness reaches $21.1 \%$ in Joint 1 with crack pattern LD1.

For Joint 2 with ductile failure modes, a relatively flat segment can be found in the load-slip curves, and a drop of capacity caused by crack propagation is observed in the joints, as shown in Fig. 14e-h. Similar to Joint 1, more decrease of capacity is observed in Joint 2 with more initial cracks, as can be found in Fig. 14e, f. Due to the existence of initial cracks, the final state of bolts with initial cracks passing through switches from producing significant bending deformation to remaining straight after applying external load. Due to the existence of initial cracks, the capacity of the bolts cannot be fully utilized, which is an intuitive reason for the decrease of capacity of joints. The decreasing ratio of joint capacity can be up to $16.5 \%$ with crack pattern named LRD2. However, Joint 2 with different numbers of 
cracks have similar initial stiffness, which is quite different from Joint 1 . Initial stiffness of Joint 2 is dominated by the bending stiffness of bolts and thus, similar initial stiffness is observed for bolted joints with different numbers of initial cracks. Comparing Fig. 14f to e, it can be seen that different crack lengths have similar effect on the capacity of joints, while longer cracks impair the initial stiffness of Joint 2 more dramatically due to more significant crack opening displacement produced in joints with initial cracks through two bolts. Compared to Joint 1, the maximum decreasing ratio of initial stiffness in Joint 2 is much lower. For Joint 2 with initial cracks through one bolt or set in the middle bolt line, bolt yielding occurs earlier than the opening and propagation of initial cracks. Thus, the cracks have little influence on the initial stiffness of joints. With initial cracks through two bolts and set on side bolt lines, more significant crack-opening displacement were produced, but the decreasing ratio of initial stiffness was still much smaller than Joint (1). It indicates that cracks have more significant effect on the initial stiffness of tension joints with brittle failure mode than those with ductile bolt yielding failure mode. Another big difference from Joint 1 is that initial cracks at different locations have different influence on the capacity of Joint (2). As can be found from Fig. 14g and h, cracks set on left and middle bolt line lead to the maximum and minimum decreasing ratio of capacity, respectively. In Joint 2, with initial cracks set in the middle bolt line, bolt yielding occurs earlier than the opening and propagation of initial cracks and thus, little influence of the cracks is observed on the capacity and initial stiffness of joints.

\section{Conclusions}

The paper presents the numerical results of bolted glulam joints under tension load. A numerical model with the introduction of initial cracks was developed and verified by the results obtained from a full-scale experiment. Hill yield criterion and CZM law were introduced in the model to simulate the bolt yielding failure and brittle failure of wood, respectively. To further investigate the effect of different crack patterns (i.e., crack lengths, crack locations and crack numbers) on the behavior of tension joints with different failure modes, a parametric study was conducted with the validated model. The following conclusions can be drawn:

1) For bolted joints with brittle failure mode, the principal factor affecting the reduction of the capacity is the crack numbers, and more decrease of capacity is observed in joints with more cracks. For bolted joints with brittle failure mode, except for crack numbers, crack locations also affect the decrease of capacity. Cracks set on side bolt lines lead to more decrease of capacity compared to cracks on middle lines.

2) In terms of the decrease of initial stiffness, for bolted joints with ductile failure mode, the principal factors include the crack lengths and crack locations, and longer cracks set on side bolt lines affect the initial stiffness more dramatically. For bolted joints with brittle failure mode, except for crack lengths and crack locations, crack numbers also affect the decrease of initial stiffness and more cracks lead to more decrease of initial stiffness of joints.

3) Compared to bolted joints with ductile failure mode, initial cracks have more significant influence on the initial stiffness of joints with brittle failure mode, which can be reduced by up to $34.8 \%$. The maximum decreasing ratios of capacity are similar for joints with brittle or ductile failure mode, which are $14.0 \%$ and $16.5 \%$, respectively.

Acknowledgements The authors gratefully acknowledge National Key R\&D Program of China (Grant No. 2017YFC0703507) for supporting this research.

\section{References}

1. Xu BH, Taazount M, Bouchaïr A, Racher P (2009) Numerical 3D finite element modelling and experimental tests for dowel-type timber joints. Constr Build Mater 23(9):3043-3052

2. EN 1995-1-1 (2004) Eurocode 5-design of timber structurespart 1-1: general-common rules and rules for buildings. European Committee for Standardization, Brussels

3. Gattesco N, Toffolo I (2004) Experimental study on multiple-bolt steel-to-timber tension joints. Mater Struct 37(2):129-138

4. Mischler A, Prion H, Lam F (2000) Load-carrying behaviour of steel-to-timber dowel connections. In: Proceedings of world conference of timber engineering, British Columbia, Canada

5. Mohammad M, Quenneville J (1999) Behaviour of wood-steelwood bolted glulam connections. CIB-W18

6. Pedersen MBU, Clorius CO, Damkilde L, Hoffmeyer P, Eskildsen L (1999) Dowel type connections with slotted-in steel plates. CIBW18 Timber Structures, Universitet Karlsruhe, pp 1-17

7. Audebert M, Dhima D, Taazount M, Bouchair A (2011) Numerical investigations on the thermo-mechanical behavior of steel-totimber joints exposed to fire. Eng Struct 33(12):3257-3268

8. Guan ZW, Zhu EC (2009) Finite element modelling of anisotropic elasto-plastic timber composite beams with openings. Eng Struct 31(2):394-403

9. Racher P, Laplanche K, Dhima D, Bouchaïr A (2010) Thermomechanical analysis of the fire performance of dowelled timber connection. Eng Struct 32(4):1148-1157

10. Kharouf N, McClure G, Smith I (2003) Elasto-plastic modeling of wood bolted connections. Computers structures 81(8):747-754

11. Moses DM, Prion HGL (2003) A three-dimensional model for bolted connections in wood. Can J Civ Eng 30(3):555-567

12. Xu BH, Bouchaïr A, Taazount M, Racher P (2013) Numerical simulation of embedding strength of glued laminated timber for dowel-type fasteners. J Wood Sci 59(1):17-23 
13. Patton-Mallory M, Pellicane PJ, Smith FW (1998) Qualitative assessment of failure in bolted connections: Tsai-Wu criterion. Journal of testing evaluation 26(5):497-505

14. Patton-Mallory M, Pellicane PJ, Smith FW (1997) Modeling bolted connections in wood. Struct Eng 123(8):1054-1062

15. Hong JP (2007) Three-dimensional nonlinear finite element model for single and multiple dowel-type wood connections. Doctor, University of British Columbia, Canada

16. Hong JP, Barrett D (2010) Three-dimensional finite-element modeling of nailed connections in wood. Struct Eng 136(6):715-722

17. Hong JP, Barrett JD, Lam F (2011) Three-dimensional finite element analysis of the Japanese traditional post-and-beam connection. J Wood Sci 57(2):119-125

18. Coureau JL, Gustafsson PJ, Persson K (2006) Elastic layer model for application to crack propagation problems in timber engineering. Wood Sci Technol 40(4):275-290

19. Resch E, Kaliske M (2010) Three-dimensional numerical analyses of load-bearing behavior and failure of multiple double-shear dowel-type connections in timber engineering. Comput Struct 88(3):165-177

20. Alfano G, Crisfield MA (2001) Finite element interface models for the delamination analysis of laminated composites: mechanical and computational issues. Int J Numer Methods Eng 50(7):1701-1736

21. Camanho PP, Dávila CG (2002) Mixed-mode decohesion finite elements for the simulation of delamination in composite materials. In: NASA/TM-2002-211737. NASA Langley Research Center, pp 1-37

22. Camanho PP, Davila C, De Moura M (2003) Numerical simulation of mixed-mode progressive delamination in composite materials. J Compos Mater 37(16):1415-1438
23. Franke B, Quenneville P (2011) Numerical modeling of the failure behavior of dowel connections in wood. J Eng Mech 137(3):186-195

24. Frühwald Hansson E, Serrano E, Toratti T, Emilsson A, Thelandersson S (2007) Design of safe timber structures (trans: Engineering DoS). How can we learn from structural failures in concrete, steel and timber. Lund Institute of Technology, Sweden

25. Sjödin J, Johansson CJ (2006) Influence of initial moisture induced stresses in multiple steel-to-timber dowel joints. Holz Roh-Werkst 65(1):71-77

26. Sjödin J (2008) Strength and moisture aspects of steel-timber dowel joints in glulam structures. Doctoral thesis, Växjö University, Sweden

27. GB/T 3098-2000 (2000) Mechanical properties of fasteners bolts, screws and studs (in Chinese). Ministry of Housing and UrbanRural Development of the People's Republic of China, Beijing

28. Saliklis EP, Urbanik T, Tokyay B (2003) Bilinear modelling of cellulosic orthotropic nonlinear materials. J Pulp Paper Sci 29:407-411

29. Jensen JL, Quenneville P (2009) Fracture mechanics analysis of row shear failure in dowelled timber connections. Wood Sci Technol 44(4):639-653

30. ASTM (2012) Standard test methods for mechanical fasteners in wood. vol D1761-12. American Society of Mechanical Engineers, West Conshohocken

31. Jorissen AJM (1998) Double shear timber connections with dowel type fasteners. Delft University Press, Delft

32. McCarthy C, McCarthy M (2005) Three-dimensional finite element analysis of single-bolt, single-lap composite bolted joints: Part II--effects of bolt-hole clearance. Compos Struct 71(2): 159-175 